DOI: https://doi.org/10.26694/ca.v1i1.10128

\title{
O VOLTAR-SE DE ARENDT ÀS ATIVIDADES DO ESPÍRITO
}

\author{
Arendt's attention to the activities of the mind
}

Maria Cristina Muller ${ }^{1}$

\begin{abstract}
RESUMO
Objetiva-se discorrer sobre as motivações que levaram Hannah Arendt a voltar sua atenção às atividades da vida contemplativa. Toma-se como justificativa a estranheza que causou a alguns o interesse de Arendt pelas atividades do espírito. Tal questionamento partiu da compreensão de que o voltar a atenção às atividades do espírito parece avesso a quem sempre fez questão de excluir-se do rol dos filósofos. Soma-se ao objetivo acima apresentar os traços característicos das atividades espirituais no sentido de compreender que tais características são inerentes às atividades do espírito, à própria experiência do pensar, do querer e do julgar e não significam desprezo pelo mundo ou desqualificação das atividades da vida ativa. $\mathrm{O}$ artigo estabelece como hipótese que uma investigação mais atenta da obra de Hannah Arendt permite comprovar que a filósofa não caíra em contradição, tampouco fora levada a reconhecer como verdadeiro o que negara anteriormente. Trata-se de pesquisa bibliográfica assentada na análise e compreensão do texto de Hannah Arendt A vida do espirito e da biografia de Arendt escrita por Elisabeth Young-Bruehl Por amor ao mundo: a vida e a obra de Hannah Arendt. Concluiu-se que a investigação acerca da vida contemplativa da condição humana realizada por Arendt não constitui uma ruptura com aquilo que a filósofa defendeu anteriormente em sua obra, mas aponta para o caminho de compreensão do ser humano em suas dimensões ativa e contemplativa. Deste modo, a obra $A$ vida do espirito consolida a proposta, sempre presente, de Arendt de investigar os dois modos de vida que compõem a condição humana, a vida ativa e a vida contemplativa, apresentando não uma distância intransponível entre elas, mas um imbricamento fundamental.
\end{abstract}

Palavras-Chave: Hannah Arendt; Atividades do espírito; Vida Contemplativa.

\begin{abstract}
The aim is to discuss the motivations that led Hannah Arendt to turn her attention to the activities of the contemplative life. The reason is the strangeness that Arendt's interest in the activities of the mind has caused to some, whose questioning arose from the understanding that turning her attention to the activities of the mind seemed averse to someone who had always made a point of excluding herself from the list of philosophers. We also address the characteristic features of the activities to understand that they are inherent to the activities of the mind, to the very experience of thinking, willing, and judging, and do not mean disdain for the world or disqualification of the activities of the active life. We start from the hypothesis that a closer investigation of Hannah Arendt's work makes it possible to prove that she has not fallen into contradiction, nor has she been led to acknowledge as true what she had previously denied. This research is bibliographical, based on the analysis, and understanding of Hannah Arendt's text The life of the Mind, and Arendt's biography by Elisabeth Young-Bruehl, For love of the world: the life and work of Hannah Arendt. We show that Arendt's research on the contemplative life of the human condition does not constitute a break with what the philosopher had previously argued in her work, but points to the understanding of the human being in his active and contemplative dimensions. Hence, The Life of the Mind consolidates Arendt's ever-present proposal to investigate the two ways of life that make up the human condition, the active and the contemplative life, not presenting an insurmountable distance between them but a fundamental interconnection.
\end{abstract}

Keywords: Hannah Arendt; Activities of the mind; Contemplative Life

\section{INTRODUÇÃO}

Objetiva-se discorrer sobre as motivações que levaram Hannah Arendt a voltar sua atenção às atividades da vida contemplativa. Toma-se como justificativa a estranheza que causou a alguns o interesse de Arendt pelas atividades do espírito. As reflexões de Hannah Arendt acerca da dimensão

\footnotetext{
1 Professora do Departamento de Filosofia da Universidade Estadual de Londrina - UEL/PR; Professora do Programa de Pós-Graduação em Filosofia da UEL; Pós-Doutorado junto ao PPGFIL da UFG (março 2018 fevereiro 2019); Doutora em Filosofia pela UFSCar, Mestre em Filosofia pela PUCRS, Graduada em Filosofia pela UPF; Estágio Pós-Doutoral junto ao Programa de Pós-Graduação em Filosofia da UFG (março 2018 fevereiro 2019). Coordenadora do GT Filosofia Política Contemporânea da ANPOF (2016-2018).
} 
da quietude humana, sobretudo o interesse por questões morais, causou estranheza, em certa medida até mesmo à filósofa, mas principalmente àqueles leitores acostumados com temas e preocupações políticas que sempre caracterizaram os interesses de Arendt. O questionamento por parte de alguns partiu da compreensão de que o voltar a atenção às atividades do espírito parece avesso a quem sempre fez questão de excluir-se do rol dos filósofos. Essa foi a perplexidade de muitos quando Arendt assumiu o desafio de refletir sobre as atividades do pensar, do querer e do julgar. A filósofa, durante muito tempo, teve como preocupação principal a investigação acerca da dimensão ativa da condição humana, com o intuito de refletir sobre a dignidade da política; criticou a filosofia por seu distanciamento das questões pertinentes à vida ativa da condição humana na pretensão de conquistar um patamar considerado por muitos filósofos "profissionais" hierarquicamente superior, por ater-se apenas a preocupações e investigações relativos à contemplação, distanciadas das questões mundanas.

Soma-se ao objetivo acima apresentar os traços característicos das atividades espirituais: invisibilidade, alheamento, estar-só, ausência de som sem ser silenciosa, re-presentação, retirar-se do mundo e incerteza. Interessa compreender que tais características da vida do espírito são inerentes às atividades do espírito, à própria experiência do pensar, do querer e do julgar e não significam desprezo pelo mundo ou desqualificação das atividades da vida ativa, as atividades realizadas no mundo, as atividades do trabalho, da obra e da ação.

O artigo estabelece como hipótese que uma investigação mais atenta da obra de Hannah Arendt permite comprovar que a filósofa não caíra em contradição, tampouco fora levada a reconhecer como verdadeiro o que negara anteriormente. Arendt estava apenas sendo coerente com sua própria percepção de filosofia, tal como se pode inferir de sua obra, isto é, a filosofia como busca de significado para as questões que tocam a vida humana. Cada interrogação posta por Arendt ao longo de sua vida e trajetória filosófica, ao ser respondida, suscitava novas perguntas, que imediatamente exigiam novas reflexões, conceitos, noções, ideias, categorias, significados. A filósofa nunca se permitiu acomodar-se diante das explicações correntes ou teorias consolidadas; seu compromisso era com a interrogação, tarefa especial da filosofia. Mas isso não significa que Arendt tenha alterado radicalmente o foco ou a direção de suas pesquisas ao final de sua vida, ao contrário. Há, sem dúvida, do início ao fim da obra de Arendt, uma recorrência a certas questões fundamentais e essa recorrência é suficiente para comprovar que há um "fio condutor" a reger as investigações da filósofa, mesmo que esse fio não permita inseri-la em um dado sistema filosófico. Entre as preocupações recorrentes de Arendt, há as que dizem respeito ao espaço público como espaço verdadeiramente humano, isso é, à participação na esfera política, o entre-os-homens, como espaço privilegiado da existência humana em que a liberdade política aflora não como fim ou objetivo da política, mas como significado da política; à fé na solidariedade entre os seres humanos enquanto respeito ao outro, ao distinto, isso é, amor - amizade - ao mundo - amor mundi.

Trata-se de pesquisa bibliográfica assentada na análise e compreensão do texto de Hannah Arendt $A$ vida do espirito. No entanto, outros textos, mesmo que não referenciados diretamente, 
compõem a pesquisa, tais como $A$ condição humana, Eichmann em Jerusalém: um relato sobre a banalidade do mal, Origens do totalitarismo, Compreensão e política, Filosofia e política, Lições sobre a filosofia política de Kant, entre outros. Outra grande referência é a biografia de Arendt escrita por Elisabeth Young-Bruehl, Por amor ao mundo: a vida e a obra de Hannah Arendt. Inicialmente discutir-se-á o voltar-se de Arendt às atividades do espírito e posteriormente, os traços característicos de tais atividades.

\title{
ATENÇÃO ÀS ATIVIDADES DO ESPÍRITO
}

A atenção de Arendt às atividades do espírito foi conhecida do público contemporâneo a ela por algumas apresentações do tema em eventos acadêmicos dos quais participou quando trabalhava nos manuscritos da obra $A$ vida do espirito. É relevante analisar como Arendt apresentou publicamente as primeiras noções de suas reflexões acerca da vida contemplativa da condição humana, pois elas delimitam em que termos ela analisou a atividade do pensar, compreensão essa que se estende às atividades do querer e do julgar. A ideia que Arendt apresentou envolvia o "pensar sem corrimão"2, que, pode-se inferir, significa o pensar que habilita o julgar sem qualquer tipo de muleta - códigos morais estatuídos, regras de conduta, mandamentos etc. - que o pudesse auxiliar ou determinar externamente. A resposta que Arendt apresentou, por exemplo, aos jovens ativistas de Toronto que desejavam dela, enquanto teórica política, um posicionamento ativo que pudesse orientar ou influenciar o público manifesta claramente a convicção da filósofa de que as atividades do espírito demandam reflexão, que é, predominantemente, pessoal; além disso, demandam liberdade. Por conseguinte, a tomada de posição no mundo também é pessoal, independente de guias.

\begin{abstract}
1. Não acredito que nós [teóricos políticos] tenhamos, ou possamos ter, tal influência nesse sentido. Eu penso que o compromisso pode facilmente levar-nos a um ponto em que não se pensa mais. Há certas situações extremas nas quais é preciso agir. Mas essas situações são extremas... e penso... o teórico que diz aos seus alunos o que pensar e como agir é... meu Deus! Eles são adultos! Não estamos no berçário. 2. Assim, acho que esse "pensar", sobre o qual escrevi e estou escrevendo agora - pensar no sentido socrático -, é uma função maiêutica, um parto. Isto é, expomos todas as nossas opiniões, preconceitos, o que for; e sabemos que nunca, em qualquer dos diálogos (platônicos), Sócrates jamais descobriu qualquer filho [da mente] que não fosse um ovo sem gema. Que se permanece de certo modo vazio após pensar... e uma vez que estamos vazios, então, de um modo que é difícil de dizer, estamos preparados para julgar. Isto é, sem ter qualquer livro de regras nas quais você possa subsumir um caso particular, você deve dizer "isto é bom", "isto é mau", "isto é certo", "isto é errado", "isto é belo", "isto é feio". E a razão pela qual acredito tanto na Crítica do juizo, de Kant, não é porque esteja interessada em estética, mas porque acredito que o modo pelo qual dizemos "isto é certo, aquilo é errado" não é muito diferente do modo pelo qual dizemos "isto é belo, isto é feio". Ou seja, estamos agora preparados para encarar os fenômenos, por assim dizer, de frente, sem qualquer sistema preconcebido. E, por favor, incluindo o meu próprio! ${ }^{3}$
\end{abstract}

2 YOUNG-BRUEHL, Elisabeth. Por amor ao mundo: a vida e a obra de Hannah Arendt. Trad. Antônio Trânsito. Rio de Janeiro: Relume-Dumará, 1997, p. 394.

3 ARENDT apud YOUNG-BRUEHL, Elisabeth. Por amor ao mundo: a vida e a obra de Hannah Arendt. Trad. Antônio Trânsito. Rio de Janeiro: Relume-Dumará, 1997, p. 393-94. A primeira citação (1.) refere-se à 
As razões pontuais que levaram Arendt a refletir sobre as atividades do espírito constam na introdução do Volume I - O Pensar - da obra A vida do espírito. É importante perceber a inquietação de Arendt diante da pretensão de refletir sobre atividades "exclusivamente" contemplativas - as atividades espirituais -; inquietação compreensível, pois, afinal, a filósofa adentraria discussões tão distintas das que comumente a cercaram. Pode-se inferir que a estranheza relatada por Arendt originava-se da posição de distanciamento adotada por ela em relação a uma tradição filosófica que sempre subjugou e menosprezou a vida ativa da condição humana, ao considerar a contemplação hierarquicamente superior. Na tentativa de amenizar esta estranheza, a filósofa apresentou duas justificativas bastante convincentes, justificativas essas necessárias à própria filósofa. A primeira relaciona-se à tese que nutria desde Eichmann em Jerusalém, isto é, à ideia de que o que faltou a esse funcionário da burocracia de Hitler foi a capacidade de pensar por si mesmo; ausência de pensamento era a questão a ser analisada; portanto, pensar o que é o pensar era inevitável. A segunda refere-se ao choque existente entre a conduta moral que pode ser observada nas experiências factuais da vida humana e aquilo que a ética e a filosofia tradicionalmente concebem como padrão de certo e de errado. Arendt se refere pontualmente a todos os acontecimentos da primeira metade do século XX - nazismo e bolchevismo - que provaram não haver limites para a brutalidade humana e para uma moralidade que se conforma exclusivamente enquanto costume facilmente cambiável.

Minha preocupação com as atividades espirituais tem origem em duas fontes bastante distintas. O impulso imediato derivou do fato de eu ter assistido ao julgamento de Eichmann em Jerusalém. Em meu relato, mencionei a "banalidade do mal" [...] Aquilo com que me defrontei, entretanto, era inteiramente diferente e, no entanto, inegavelmente factual [...] a única característica notória que se poderia perceber tanto em seu comportamento anterior quanto durante o próprio julgamento [...] era algo de inteiramente negativo: não era estupidez, mas irreflexão. [...] Foi essa ausência de pensamento [...] que despertou meu interesse. [...] Mas, além disso, também essas questões morais que têm origem na experiência real e se chocam com a sabedoria de todas as épocas [...] renovaram em mim certas dúvidas $\left[\ldots . .{ }^{4}\right.$

A ausência de pensamento, a irreflexão, não a estupidez ou uma mente demoníaca, exemplificada na figura de um homem - Eichmann -, levou Arendt a questionar se a falta de pensamento pode conduzir ao mal; por isso é preciso saber o que é o Pensar. Este questionamento surgiu como um impulso imediato à Arendt após assistir ao julgamento do oficial nazista em Jerusalém. A carência - a negação - de uma das atividades que caracteriza a condição humana fez com que viesse à tona a necessidade de se investigar tal capacidade. Pode-se inferir que o exemplo desprezível do não pensar motivaram Arendt a investigar o que era o Pensar. A filósofa havia constatado que aquele homem era absolutamente superficial, ele não possuía nenhuma das características que costumeiramente poderiam ser atribuídas a um indivíduo capaz de cometer

conferência na Universidade York em Toronto/Canadá; a segunda (2.), à conferência da Sociedade Americana pela Ética Cristã.

4 ARENDT. Hannah. A vida do espirito: o Pensar, o Querer, o Julgar. 3. ed. Trad. Antonio Abranches; César Augusto R. de Almeida; Helena Martins. Rio de Janeiro: Relume-Dumará, 1995, p. 5 a 7. 
desumanidades. Contudo, o mal que cometera era inegavelmente real e absurdamente bárbaro. E este paradoxo - superficialidade do perpetrador do mal, brutalidade do mal cometido - causava assombro. Não havia profundidade naquele homem, tampouco nos motivos que o fizeram cometer tantas indignidades. Se nenhuma das respostas comuns à questão do mal eram capazes de explicar as atitudes daquele homem, restava empreender uma nova investigação. $\mathrm{O}$ que estava patente no mal cometido por aquele oficial nazista era a incapacidade daquele pensar com alargamento.

A mentalidade alargada 5 é a capacidade de pensar a partir da perspectiva do outro, da pluralidade; na esfera da ação, diz respeito à capacidade de se colocar diante e no lugar daqueles que sofrerão as consequências da ação, portanto, está intimamente ligada à capacidade de julgar. Eichmann não conseguiu pensar sob outras perspectivas, tampouco se colocar no lugar daqueles que sofreriam as consequências da sua decisão. Infelizmente, segundo Arendt, isso não era uma característica unicamente daquele homem específico, mas de toda uma sociedade, a sociedade massificada, que perdera a capacidade de pensar por si mesma. Nas palavras da filósofa: “[...] uma experiência tão comum em nossa vida cotidiana, em que dificilmente temos tempo e muito menos desejo de parar e pensar [...].”

A segunda motivação que levou Arendt a discutir as atividades da vida contemplativa da condição humana diz respeito aos conflitos morais que surgiram da experiência totalitária da Alemanha Nazista. Os critérios de certo e errado a que as pessoas estavam acostumadas foram alterados da noite para o dia e essa alteração nada causou de assombro ou perplexidade para a maioria delas. Fatos assustadores, como, por exemplo, delatar vizinhos, presenciá-los sair obrigados de suas casas, caminhando pacificamente para guetos e depois para os campos de extermínio, foram vistos com normalidade, pois retratavam as ordens e a condução do governo. As ordens e as leis deveriam ser obedecidas e não questionadas. Eram raros os que se viam frente a algum tipo de conflito moral, pois o esperado era a obediência. Condutas de obediência cega é o esperado diante da completa ausência de pensamento reflexivo, ausência de pensar por si mesmo.

As ações, da maioria, de uma sociedade - a sociedade alemã à época do nazismo - e os critérios de estabelecimento do certo e do errado dessa mesma sociedade, como exposto, confirmaram a percepção de Arendt de que as questões morais advindas da experiência haviam colidido com aquilo que se sabia e que se tinha até então como verdades da filosofia e da ética. Isto é, uma das verdades da filosofia, desde Platão, dizia respeito ao fato de se acreditar que o "pensamento" produzia o bem. Mas, "pensamento" enquanto uma faculdade que comporta em si a verdade absoluta como regra geral para subsumir casos particulares. Essa compreensão de "pensamento" corresponde à cognição, ao intelecto, não à razão, diferença essa fundamental para

\footnotetext{
${ }^{5}$ É importante apontar que o pensar com alargamento ou a mentalidade alargada é um conceito que Arendt utilizou em vários textos, como, por exemplo, no texto Liç̃és sobre a Filosofia Politica de Kant, quando discutiu o conceito de pluralidade humana como indispensável para o entendimento humano e no texto $A$ condição bumana, para discutir a ideia da revelação do agente e a condição básica para a ação e para o discurso.

6 ARENDT. Hannah. A vida do espirito: o Pensar, o Querer, o Julgar. 3. ed. Trad. Antonio Abranches; César Augusto R. de Almeida; Helena Martins. Rio de Janeiro: Relume-Dumará, 1995, p. 6.
} 
Arendt. Apesar da convicção corrente de que "pensamento" produzia o bem, não foi isso que a sociedade alemã demonstrou na prática. Portanto, a concepção de "pensamento" a que se referia a tradição filosófica desde Platão, para Arendt, não produz o bem como resultado inevitável, como se as virtudes pudessem ser ensinadas. Para a filósofa, hábitos e costumes podem ser ensinados e aprendidos, como também podem ser facilmente e rapidamente substituídos por outros quando assim for conveniente. $\mathrm{O}$ exemplo claro disso pode ser percebido na inversão, ocorrida durante o totalitarismo nazista, no mandamento "Não Matarás" para "Matarás".

Tudo isso parece ter renovado em Arendt as dúvidas que ela sempre nutriu acerca da moralidade e acerca daquilo que a filosofia asseverava ser a esfera contemplativa, mais especificamente, o pensar. As respostas que a tradição filosófica oferecia às atividades da vida contemplativa nunca haviam convencido Arendt; além disso, os exemplos advindos dos regimes totalitários e da sociedade totalitária confirmaram as suspeitas da filósofa de que as doutrinas morais existentes - derivadas das verdades da tradição -, que serviam de padrão para julgar o certo e o errado e para conduzir a ação humana na esfera pública do mundo, não obtinham necessariamente resultados acertados.

\section{OS TRAÇOS CARACTERÍSTICOS DAS ATIVIDADES ESPIRITUAIS}

As atividades espirituais, segundo a compreensão de Arendt, são basicamente três: Pensar, Querer, Julgar. São atividades independentes entre si, no sentido de que cada uma delas segue leis intrínsecas à própria atividade. Apresentam como característica comum a dependência de uma certa quietude. Essa quietude diz respeito a um apartar do espírito das emoções da alma e das sensações da percepção; por isso, pode ser comparado a uma tranquilidade desapaixonada. Essa quietude não é uma qualidade necessária para que as atividades espirituais possam acontecer, uma vez que dela não decorre necessariamente que as atividades do espírito acontecerão. Isto significa, em outras palavras, que as atividades espirituais não estão condicionadas a qualquer coisa.

Os seres humanos é que são seres condicionados existencialmente. As condições da existência humana são a própria vida, a natalidade e a mortalidade, a mundanidade, a pluralidade e o planeta Terra. O ser humano está restrito ao espaço de tempo entre seu nascimento e sua morte, obrigado ao trabalho (animal laborans) para manter sua vida, impelido à fabricação (bomo faber) para criar um mundo artificial que possa chamar de sua morada e estimulado a agir para encontrar seu lugar de reconhecimento entre os muitos indivíduos diferentes que existem.

$\mathrm{Na}$ esfera da quietude, nenhuma das condições da vida e do mundo lhe corresponde. Apesar disso, é certo que aquilo de que as atividades espirituais se ocupam - "objetos" do pensar, do querer e do julgar - são oferecidas pelo mundo, pela vida dos seres humanos no mundo. Mesmo que os seres humanos sejam condicionados existencialmente, não ficam restritos à dimensão existencial; podem transcender - aquietar-se - espiritualmente; os seres humanos podem indagar 
ilimitadamente sobre qualquer tema, podem imaginar qualquer existência, podem inclusive especular sobre aquilo que não conhecem, sobre aquilo de que nem pode haver conhecimento.

Os princípios da ação e os critérios dos juízos são elaborados pelo espírito. Isso é, as atividades do espírito preparam o ser humano para a ação. Mas isso não significa que as atividades espirituais se constituem em ação ou que as atividades do espírito dotam os seres humanos diretamente com o poder de agir. A ação, propriamente dita, é uma atividade que corresponde à vida ativa da condição humana, está condicionada à existência humana.

[...] Os homens podem julgar afirmativa ou negativamente as realidades em que nascem e pelas quais são também condicionados; podem querer o impossível, como, por exemplo, a vida eterna; e podem pensar, isto é, especular de maneira significativa sobre o desconhecido e o incognoscível. E embora isto jamais possa alterar diretamente a realidade - como de fato não há, em nosso mundo, oposição mais clara e mais radical do que a oposição entre pensar e fazer -, os princípios pelos quais agimos e os critérios pelos quais julgamos e conduzimos nossas vidas dependem, em última instância, da vida do espírito. Em suma, dependem do desempenho aparentemente não lucrativo dessas empresas espirituais que não produzem resultados e "não nos dotam diretamente com o poder de agir" (Heidegger). [...]..$^{7}$

Pode-se inferir que o que talvez seja mais belo na discussão de Arendt e uma de suas maiores contribuições à filosofia é a consideração livre e aberta de que os seres humanos, ao mesmo tempo em que são condicionados existencialmente, podem transcender espiritualmente. $\mathrm{E}$ disso resulta outra grande contribuição de Arendt à filosofia, a saber, que não há necessidade de nenhuma hierarquização ou predominância de uma das condições humanas - vida ativa (condições existenciais) e vida contemplativa (vida do espírito) - sobre a outra, do enaltecimento de uma em detrimento da outra.

Tomando-se como referência o mundo das aparências, a principal característica das atividades espirituais é a invisibilidade - algo que é, mas que não se manifesta aos olhos. As atividades espirituais são manifestas para o ego pensante, volitivo e judicante, que percebe que elas estão em movimento; entretanto, as atividades espirituais, literalmente falando, não podem aparecer no mundo das aparências porque lhes falta esta habilidade.

Ao se tomar os aspectos de visibilidade e invisibilidade, percebe-se que há vários graus de manifestação das atividades da condição humana. Mesmo o trabalho e a obra, que pertencem à vida ativa da condição humana, não requerem o espaço da aparência - espaço público - para a efetivação de suas atividades próprias. Essas atividades acontecem independentemente da companhia dos demais; o ser humano se isola para trabalhar e fabricar. Somente a ação e a fala dependem de um espaço da aparência, de um espaço em que há outras pessoas que vejam e ouçam, para se cumprir completamente, para se efetivar. As demais atividades prescindem deste espaço.

A única manifestação externa do espírito é o alheamento, isto é, aquela completa e radical falta de atenção em relação ao mundo das aparências, o afastar, o apartar, o alienar em relação ao

7 ARENDT. Hannah. A vida do espirito: o Pensar, o Querer, o Julgar. 3. ed. Trad. Antonio Abranches; César Augusto R. de Almeida; Helena Martins. Rio de Janeiro: Relume-Dumará, 1995, p. 56. Sem grifos no original. 
mundo que cerca os seres humanos. Pode-se inferir que o mais interessante, e que talvez seja a garantia da liberdade nas atividades da vida do espírito, seja o fato de que, mesmo que haja certa exteriorização através do alheamento, quando o indivíduo se vê absorto nas atividades do espírito, é impossível saber o que se passa internamente neste indivíduo. Oxalá que isto permaneça infinitamente.

Outra característica marcante da vida do espírito é o estar só, estar sozinho, e estabelecer um relacionamento consigo mesmo. Os atos do espírito, mesmo o de pensar, nunca se satisfazem com os seus objetos tal como lhe são dados. O espírito inevitavelmente transcende a pura imediatez daquilo que tenha lhe chamado a atenção e transforma isso num experimento do eu-comigo-mesmo experimentum suitatiss. Estar sozinho e estabelecer um relacionamento consigo mesmo é, para Arendt, o que atribui uma marca definitiva à vida do espírito. Infere-se que, neste momento, o espírito sozinho consigo mesmo - alcança "vida própria" e aquilo que anteriormente - no espaço da aparência, no espaço entre-os-homens - era chamado de pluralidade passa a ser, em termos existenciais, o conhecer comigo mesmo. O conhecer comigo mesmo é a definição que Arendt dá à consciência. Mesmo sendo este um dos trechos de maior dificuldade de análise da obra $A$ vida do Espirito, pode-se inferir que, com esta argumentação, Arendt estabelece nitidamente em que termos - o da consciência - sua investigação se refere à vida do espírito e a suas correspondentes atividades mentais básicas - pensar, querer, julgar.

A este estado espiritual em que o ser humano faz companhia apenas e tão somente para ele mesmo, Arendt prefere chamar de "estar só", para que não haja confusão com a ideia que o termo “solidão" apresenta. Solidão se relaciona ao estado existencial em que o ser humano não apenas abdica da companhia dos outros seres humanos, mas abandona a companhia dele mesmo. Isso não é o caso das atividades do espírito, em que, mesmo que o indivíduo se prive da companhia do outro e da pluralidade que os outros representam, ele assume a plena consciência dessa situação, conseguindo, assim, existir absolutamente no singular.

Para Arendt, a vida do espírito não é silenciosa. Ela pode não ter som, mas jamais é silenciosa. A vida do espírito também jamais esquece completamente de si graças à natureza reflexiva das suas atividades básicas: “[...] todo cogitare, não importa qual seja seu objeto, é também um cogito me cogitare; toda volição é um volo me velle; mesmo o juízo só é possível por um 'retour secret sur moi-même', como observou Montesquieu. [...].”’. Essa reflexividade - o não esquecer de si -

\footnotetext{
8 Este termo foi cunhado por filósofo do século XIII chamado Petrus Johannis Olivi - considerado o filósofo franciscano da Vontade - e advém provavelmente da antiga abordagem romana que considerava o inter homines esse - o estar entre os homens - como sinal de os seres humanos estarem vivos, isto é, cientes da realidade do mundo e do Eu. O inter homines esse desinere - deixar de estar entre os homens - era sinônimo de morrer. Para a pluralidade humana - condição da ação e do discurso - é imprescindível o inter homines esse, o estar entre os homens. A pluralidade é uma das condições existenciais básicas da vida humana na Terra e, pode-se dizer, está em oposição ao inter homines esse desinere, deixar de estar entre os seres humanos (ARENDT. Hannah. A vida do espírito: o Pensar, o Querer, o Julgar. 3. ed. Trad. Antonio Abranches; César Augusto R. de Almeida; Helena Martins. Rio de Janeiro: Relume-Dumará, 1995, p. 58).

9 ARENDT. Hannah. A vida do espírito: o Pensar, o Querer, o Julgar. 3. ed. Trad. Antonio Abranches; César Augusto R. de Almeida; Helena Martins. Rio de Janeiro: Relume-Dumará, 1995, p. 59.
} 
gerou certos equívocos: entendeu-se a interioridade como lugar de ação. Isso leva Arendt a sinalizar mais uma das falácias metafísicas. Mas por que é uma falácia entender que a interioridade, a vida do espírito, é lugar de ação, ou, mais especificamente, que "pensar é agir"? A confusão muito provavelmente surgiu porque só é possível perceber as atividades do espírito quando essas atividades estão ativas, como se a existência dos órgãos do pensamento, da vontade e do juízo só viessem a existir quando o indivíduo pensa, quer e julga. A solução ao equívoco é muito simples, basta compreender que a ocupação do pensamento não pode absolutamente ser entendida como lugar de ação por que sua ocupação é eminentemente solitária - é estar só. A ação, propriamente dita, somente acontece “'em conjunto', em companhia de e em concordância com nossos pares, e, portanto, em uma situação existencial que efetivamente impede o pensamento [...]." ${ }^{10}$. Arendt menciona que Hegel é o mais relevante dos filósofos nessa discussão, pois foi ele quem estabeleceu nitidamente, principalmente no Prefácio a Fenomenologia do Espirito, a luta interna entre a filosofia e o senso comum. Hegel considerava que a intensidade das experiências do ego pensante derivaria do fato de elas serem pura atividade; também sabia da reflexividade do espírito e aceitava que ele destruísse seu próprio resultado. "A vida do espírito [...] é pura atividade. E essa atividade, assim como qualquer outra, pode ser iniciada e paralisada à vontade."11. Contudo, ele transformava em conhecimento dogmático, em resultados da cognição, os insights acerca do que a razão está fazendo quando - do ponto de vista das aparências - não está fazendo nada - pensando.

Não se pode esquecer, todavia, que as atividades do espírito - que não aparecem acontecem em um ser que é do mundo e que participa desse mundo através de seus órgãos sensoriais e da capacidade e da necessidade de também aparecer. Mas as atividades do espírito somente podem existir quando o indivíduo se retira deliberadamente da esfera das aparências. Não se trata de um retirar-se ipsis litteris do mundo, mas um retirar-se do mundo presente aos sentidos com exceção dos pensamentos que se alheiam completamente do mundo. Em linguagem metafórica, seria como se o ser humano se retirasse para ilhas imaginárias, a terra dos invisíveis, do qual nada se poderia saber, não fosse esta faculdade - pensar - que o ser humano tem de lembrar e de imaginar.

Outra característica do espírito se apresenta: a re-presentação, fazer presente o que está ausente. Todos os atos do espírito repousam nesta faculdade de ter presente para si o que está ausente aos sentidos; trata-se do que Kant nomeou de imaginação. Não estão apenas re-presentadas as imagens espirituais de objetos ausentes, mas de tudo que não é mais ou que ainda não é.

[...] somente pela capacidade do espírito tornar presente o que está ausente é que podemos dizer "não mais", e constituir um passado para nós mesmos, ou dizer "ainda não", e nos

\footnotetext{
10 ARENDT. Hannah. A vida do espirito: o Pensar, o Querer, o Julgar. 3. ed. Trad. Antonio Abranches; César Augusto R. de Almeida; Helena Martins. Rio de Janeiro: Relume-Dumará, 1995, p. 71.

11 ARENDT. Hannah. A vida do espirito: o Pensar, o Querer, o Julgar. 3. ed. Trad. Antonio Abranches; César Augusto R. de Almeida; Helena Martins. Rio de Janeiro: Relume-Dumará, 1995, p. 57.
} 
preparar para o futuro. Mas isso só é possível para o espírito depois de ele ter se retirado do presente e das urgências da vida cotidiana. [...]. ${ }^{12}$

Não é possível estabelecer uma ordem hierárquica para as atividades do espírito, mas há, sem dúvida, uma ordem de prioridades. O pensar é a atividade que de-sensorializa os particulares, isto é, a atividade do pensar prepara os particulares dados aos sentidos para que o espírito seja capaz de lidar com eles na ausência desses particulares. O pensar não pode mover a vontade, tampouco prover o juízo, mas os prepara. "A imaginação, portanto, que transforma um objeto visível em uma imagem invisível, apta a ser guardada no espírito, é a condição sine qua non para fornecer ao espírito objetos-de-pensamento adequados [...]."13. A faculdade da imaginação torna presente o que está ausente em uma forma dessensorializada. Por conseguinte, o espírito aprende a lidar com as coisas ausentes e se prepara para o entendimento delas. Além disso, o espírito se prepara para aquelas coisas que não podem ser lembradas pela memória, porque nunca estiveram presentes para a experiência dos sentidos; se prepara para aquelas coisas que, mesmo não existindo sensorialmente, podem ser pensadas.

Para a filósofa, esta classe de objetos-de-pensamento, sejam eles ideias, conceitos, categorias etc., se tornou o tema da filosofia profissional, mas isto não significa que os tópicos que a filosofia escolheu não venham das experiências do senso comum. O que precisa ser observado é a retirada do mundo das aparências. Assim, a única condição anterior essencial para o pensar - a busca de significado, não apenas de "questões últimas" irrespondíveis - é o retirar-se do mundo das aparências; o pensamento implica lembrança, é um re-pensar, interrompe o fazer e implica um parae-pense.

Um leitor desavisado poderia entender a argumentação de Arendt acerca da retirada do mundo das aparências como revisões da filósofa a seu posicionamento anterior referente à importância da vida ativa da condição humana e à sua crítica a toda história da filosofia, que sempre fez questão de fugir dos assuntos humanos, e, por conseguinte, dos assuntos políticos. No entanto, essa pesquisa infere que não é isso que Arendt está propondo; a filósofa não está absolutamente revisando sua teoria e corrigindo-a. Arendt está estabelecendo aquilo que é próprio a cada uma das atividades humanas e, com isso, consegue estabelecer uma compreensão dos motivos que levaram os filósofos a estabelecer um distanciamento entre a atividade do filosofar e as demais atividades humanas - e isso Arendt já havia proposto como tarefa desde $A$ condição humana. Pode-se entender que os traços que são próprios da vida do espírito, tais como quietude, estar só, invisibilidade, retirar-se do mundo das aparências, levaram muitos a confundir tais características com as condições ideais para que o filosofar se efetivasse. Isso Arendt não propõe ou sequer sugere; todas as características da vida do espírito são inerentes à própria atividade, à própria experiência do

12 ARENDT. Hannah. A vida do espirito: o Pensar, o Querer, o Julgar. 3. ed. Trad. Antonio Abranches; César Augusto R. de Almeida; Helena Martins. Rio de Janeiro: Relume-Dumará, 1995, p. 60.

13 ARENDT. Hannah. A vida do espirito: o Pensar, o Querer, o Julgar. 3. ed. Trad. Antonio Abranches; César Augusto R. de Almeida; Helena Martins. Rio de Janeiro: Relume-Dumará, 1995, p. 61. 
pensar, do querer e do julgar; não são privilégio do filosofar. Por outro lado, também não se pode dizer que Arendt está fazendo a defesa do empirismo:

Não é a percepção sensorial, na qual experimentamos as coisas que estão diretamente à mão, mas a imaginação, que vem depois dela, que prepara os objetos de nosso pensamento. Antes de levantarmos questões tais como "o que é a felicidade", "o que é a justiça", "o que é o conhecimento" e assim por diante, é preciso que tenhamos visto gente feliz e infeliz, que tenhamos testemunhado atos justos e injustos, experimentado o desejo de conhecer, sua boa realização ou sua frustração. Além do mais, temos que repetir a experiência direta em nossos espíritos depois de ter abandonado a cena em que ela ocorreu. Repetindo, todo pensar é um re-pensar. Ao repetir na imaginação, nós dessensorializamos qualquer coisa que tenha sido dada aos nossos sentidos. Somente nessa forma imaterial é que nossa faculdade de pensar pode começar a se ocupar com esses dados. Essa operação precede todos os processos de pensamento, tanto o pensamento cognitivo quanto o pensamento sobre significados. [...] Em outras palavras: todo pensamento deriva da experiência, mas nenhuma experiência produz significado ou mesmo coerência sem passar pelas operações de imaginação e pensamento. [...]..$^{14}$

Nessa citação, vê-se outro problema: se a própria filósofa defende e chama atenção para a diferença entre intelecto e razão, pensar e conhecer, verdade e significado, por que ela utiliza as expressões "pensamento cognitivo" e "pensamento sobre significados"? Parece que Arendt utiliza o termo pensamento como se houvesse dois modos de pensar, isto é, o modo da cognição e o modo do significado, como se coubesse ao pensamento a tarefa do conhecimento. É possível inferir que Arendt deparou-se, aqui, com uma dificuldade que em outra oportunidade ela mencionou: a dificuldade de se encontrar na linguagem corrente termos adequados ou mais bem cunhados para expressar o que se pretende, ou seja, uma abordagem diferenciada das tradicionais ou das que a tradição impõe. Por mais que se tenha cuidado ou que se tente fugir das armadilhas geradas pela falta de um vocabulário adequado à complexidade da discussão, fica-se preso à linguagem da qual dispomos. Portanto, esta pesquisa comparte da ideia de que não se trata de um erro conceitual ou uma divergência da filósofa com o que havia apregoado anteriormente, mas apenas uma dificuldade de exposição de uma ideia com o vocabulário disponível e com as possibilidades de seu uso.

Outro traço relevante da vida contemplativa é a incerteza e a impossibilidade de verificação dos resultados. Isso fica claro quando se analisam os pensamentos: é como se eles fossem autodestrutivos, uma vez que os resultados que alcançam são colocados à dúvida continuamente. $\mathrm{O}$ espírito tem aversão às certezas últimas, repudia a impossibilidade de colocar à prova, ou seja, ele duvida de algo mesmo depois que tenha encontrado alguma segurança acerca desse algo. Por isso, uma boa metáfora para o pensamento pode ser o de que o pensamento é como a teia de Penélope ${ }^{15}$, que desfaz toda a manhã o que terminou de fazer na noite anterior. A necessidade de pensar nunca pode ser satisfeita.

\footnotetext{
14 ARENDT. Hannah. A vida do espirito: o Pensar, o Querer, o Julgar. 3. ed. Trad. Antonio Abranches; César Augusto R. de Almeida; Helena Martins. Rio de Janeiro: Relume-Dumará, 1995, p. 67 e 68.

15 Arendt diz que Platão fez menção à teia de Penélope em Fédon 84a, mas de maneira inversa a que ela utiliza, isto é, que a alma do filósofo não deve agir como Penélope desfazendo sua própria teia. (ARENDT. Hannah.
} 
É importante compreender que a retirada do mundo das aparências ou mundo do senso comum, a tendência autodestrutiva em relação aos seus próprios resultados, a reflexividade e consciência da pura atividade que a acompanha e a percepção das atividades espirituais somente enquanto perdurarem são características que se apresentam mais claramente na atividade do pensar, pois ela radicaliza sua retirada do mundo. $\mathrm{O}$ querer e o juízo não têm a mesma radicalidade de retirada do mundo das aparências. No entanto, ambas as atividades do espírito compartilham de tais características em alguma medida. Para esta pesquisa é suficiente dizer que os objetos do querer e do juízo são particulares e têm seu lar estabelecido no mundo das aparências. O espírito volitivo ou judicante se retira temporariamente do mundo das aparências, mas conserva a intenção de retornar posteriormente, uma vez que os objetos dos quais tratam o querer e o juízo são o mundo.

\section{CONSIDERAÇÕES FINAIS}

Ressalta-se que a investigação acerca da vida contemplativa da condição humana não constitui uma ruptura com aquilo que Arendt defendeu anteriormente em sua obra, mas aponta para um caminho de compreensão do ser humano em suas dimensões ativa e contemplativa. Arendt quer encontrar significado para a condição humana, o modo como é estabelecido o certo e o errado, o bem e o mal, como os seres humanos se posicionam no mundo. Nesse sentido, a obra A vida do espirito consolida a proposta, sempre presente, de Arendt de investigar os dois modos de vida que compõem a condição humana, a vida ativa e a vida contemplativa, apresentando não uma distância intransponível entre elas, mas um imbricamento fundamental. Essa ideia fica clara quando Arendt aponta para a responsabilidade de cada indivíduo - esfera da quietude - pelo espaço comum - público - do mundo. Portanto, mesmo que Arendt se volte para a dimensão da quietude humana, é ao homem de ação que sua reflexão converge.

\section{REFERÊNCIAS BIBLIOGRÁFICAS}

ARENDT. Hannah. A vida do espirito: o Pensar, o Querer, o Julgar. 3. ed. Trad. Antonio Abranches; César Augusto R. de Almeida; Helena Martins. Rio de Janeiro: Relume-Dumará, 1995.

YOUNG-BRUEHL, Elisabeth. Por amor ao mundo: a vida e a obra de Hannah Arendt. Trad. Antônio Trânsito. Rio de Janeiro: Relume-Dumará, 1997.

A vida do espirito: o Pensar, o Querer, o Julgar. 3. ed. Trad. Antonio Abranches; César Augusto R. de Almeida; Helena Martins. Rio de Janeiro: Relume-Dumará, 1995, p. 172, nota 43). 


\section{BIBLIOGRAFIA}

ARENDT. Hannah. A condição bumana. Tradução de Roberto Raposo; Revisão e apresentação de Adriano Correia. 11. ed. Revisada. Rio de Janeiro: Forense Universitária, 2010.

. Eichmann em Jerusalém: um relato sobre a banalidade do mal. Trad. José Rubens Siqueira. São Paulo: Companhia das Letras, 1999.

- Origens do Totalitarismo: Anti-Semitismo, Imperialismo, Totalitarismo. Trad. Roberto Raposo. São Paulo: Companhia das Letras, 1997.

Filosofia e política. In: ARENDT. Hannah. A Dignidade da Política: ensaios e conferências. Trad. Helena Martins. Rio de Janeiro: Relume-Dumará, 1993.

Compreensão e política. In: ARENDT. Hannah. A Dignidade da Política: ensaios e conferências. Trad. Helena Martins. Rio de Janeiro: Relume-Dumará, 1993.

Lições sobre a Filosofia política de Kant. Trad. André Duarte de Macedo. Rio de Janeiro: Relume-Dumará, 1993. 